Therapeutic Drug Monitoring 2020 ;Volum 43.(1) s. 116-125 (DOI:

10.1097/FTD.0000000000000806)

\title{
Establishing Serum Reference Ranges for Antihypertensive Drugs
}

Stine Rognstad ${ }^{1,2,3}$ MD, Camilla Lund Søraas ${ }^{3,4}$ MD PhD, Ola Undrum Bergland ${ }^{2,3}$ MD, Aud Høieggen $2,3,5$ MD PhD, Magnus Strømmen ${ }^{6,7}$ RN MSc, Arne Helland ${ }^{8,9}$ MD PhD / Mimi Stokke Opdal ${ }^{1,2}$ MD PhD

${ }^{1}$ Dept. of Pharmacology, Oslo University Hospital, Ullevål, Oslo, Norway

${ }^{2}$ Institute of Clinical Medicine, University of Oslo, Oslo, Norway

${ }^{3}$ Section of Cardiovascular and Renal Research, Oslo University Hospital, Ullevål, Oslo, Norway

${ }^{4}$ Unit of Environmental and Occupational Medicine, Oslo University Hospital, Ullevål, Oslo, Norway

${ }^{5}$ Dept. of Nephrology, Oslo University Hospital, Ullevål, Oslo, Norway

${ }^{6}$ Center for Obesity Research, St. Olav University Hospital, Trondheim, Norway

${ }^{7}$ Dept. of Clinical and Molecular Medicine, Norwegian University of Science and Technology

${ }^{8}$ Dept. of Clinical Pharmacology, St. Olav University Hospital, Trondheim, Norway

${ }^{9}$ Dept. of Clinical and Molecular Medicine, Norwegian University of Science and Technology, Trondheim, Norway

\section{Corresponding author:}

Stine Rognstad, Department of Pharmacology and Section of Cardiovascular and Renal Research, Oslo University Hospital, Ullevål, Oslo, Norway and Institute of Clinical Medicine, Medical Faculty, University of Oslo. Mail address: stirog@ous-hf.no. Mobile: +4799435753

\section{Acknowledgments:}

This work is part of the National mapping- and harmonization project in clinical pharmacology initiated by the Norwegian Association of Clinical Pharmacology (NFKF). 
Associate professors Arne Helland and Mimi Stokke Opdal have contributed equally as last authors of this paper.

The authors gratefully acknowledge the analytical work from participating laboratories at the Department of Clinical Pharmacology, St Olav University Hospital, and at the Department of Pharmacology, Oslo University Hospital, Ullevål. We would like to thank the employees and leaders at these institutions for their excellent collaboration and for providing good working facilities.

The authors sincerely thank Professor Sverre E. Kjeldsen, Department of Cardiology, Oslo University Hospital, Ullevål, for commenting on this paper.

Valuable contribution from the IDA Study Group is also much appreciated.

This work was presented as a poster at the Summer School arranged by the European Society of Hypertension (ESH) in 2019, and an abstract has been accepted at the ESH-ISH meeting in 2020.

\section{Disclosure of funding received:}

This work was funded by the Research Council of Norway and by the participating Departments.

The collection of data in the study on pharmacokinetics in obese patients was partly financed via FFU The Joint Research Committee between St. Olavs University Hospital and the Norwegian University of Science and Technology (BAR-MEDS, grant ref. 2017/38202).

\section{Conflict of interest}

The authors declare no conflicts of interest. 


\section{Abstract}

BACKGROUND: Therapeutic drug monitoring (TDM) involves the measurement of serum drug concentrations to optimize pharmacotherapy. Traditionally, blood pressure measurements alone, and not TDM, have been used to evaluate the antihypertensive drug response. However, approximately $50 \%$ of hypertensive patients treated with lifestyle changes and antihypertensive drugs fail to achieve blood pressure control. Serum drug concentration measurements could be useful to select the optimal drugs in adjusted doses and to identify non-adherence. Implementation of TDM in clinical routine for antihypertensive drugs depends on established serum reference ranges.

METHODS: Commonly used antihypertensive drugs were identified based on prescription data. The authors performed a review of authoritative literature on reported serum drug concentrations and calculated expected concentrations from previously reported pharmacokinetic parameters with commonly prescribed daily doses. Finally, serum drug concentrations in samples from patients undergoing antihypertensive treatment were measured.

RESULTS: Serum reference ranges for 24 frequently used antihypertensive drugs were established based on results from three approaches.

CONCLUSION: Serum drug concentration measurements, interpreted in light of the established reference ranges, together with blood pressure measurements and other clinical data, may help identify non-adherent patients and tailor individual antihypertensive treatment when deviant drug responses appear, in line with the concept of personalized medicine.

Keywords: therapeutic drug monitoring (TDM), serum drug concentration, antihypertensive drugs, adherence, personalized medicine. 


\section{Background}

High blood pressure (BP) globally affects $30-45 \%$ of the adult population and is a major risk factor for morbidity and mortality ${ }^{1-3}$. Therefore, controlling high BP is of great importance to the health and wellbeing of a large portion of the adult population.

According to the 2018 ESH/ESC Guidelines for the treatment of hypertension, ${ }^{1}$ the recommended antihypertensive drugs are: angiotensin-converting enzyme inhibitors (ACEIs), angiotensin II receptor blockers (ARBs), calcium channel blockers (CCBs), beta-blockers, thiazide diuretics and, in certain settings, other drugs like aldosterone antagonists, loop diuretics, and alpha-blockers. In Norway, a total of 498-526 million daily defined doses (DDD) of these drug groups were prescribed yearly during 20142018 , with a reported drug expenditure of around 100 million Euros per year. ${ }^{4}$

Traditionally, BP measurements are used to evaluate the antihypertensive drug response. However, approximately $50 \%$ of those receiving treatment for hypertension fail to achieve treatment goals despite advice regarding lifestyle changes and prescription of antihypertensive medication. ${ }^{1,5}$ Uncontrolled hypertension can be attributed to poor drug adherence, suboptimal drug selection for the individual patient, failure to intensify treatment (i.e. physician's inertia), secondary hypertension, and true treatment-resistant hypertension. ${ }^{1,6}$

The prevalence of non-adherence varies and depends on the population. In small groups with apparently resistant hypertension, defined as BP $>140 / 90 \mathrm{~mm} \mathrm{Hg}$, despite treatment with diuretics and 2 other antihypertensive drugs belonging to different classes at adequate doses, several studies have reported a high prevalence of poor drug adherence, ranging between $23-66 \%{ }^{7}$ In an outpatient hypertension clinic of a university hospital, the prevalence was shown to be only $10 \%{ }^{8}$ Hence, adherence issues are not the only explanation for the high number of patients failing to achieve BP control. Large outcome trials in hypertension have shown that physician's inertia is a major cause of not 
reaching the target BP. ${ }^{9}$ Furthermore, even in adherent patients, individual pharmacokinetic variations may cause treatment failure.

Current methods for monitoring drug adherence can be unreliable (e.g. pill counting, self-reporting, patient interviews), or costly and difficult to implement in clinical practice (e.g. electronic pill dispensers, witnessed drug intake $\left.e^{7,10,11}\right)$. Quantification of the serum drug concentration, also called therapeutic drug monitoring (TDM), is an objective approach to assess adherence, may improve drug therapy, and is in line with the concept of personalized medicine. ${ }^{12-14}$ TDM is currently performed as part of the normal routine; e.g. antiepileptic, immunomodulatory, and certain psychotropic drugs. Several methods for measuring serum or blood concentrations of antihypertensive drugs by ultra-high-performance liquid chromatography coupled with tandem mass spectrometry (UHPLC-MSMS) have been published. ${ }^{15-18}$ To date, this method has mainly been used to assess drug adherence. . $^{71,19,20}$

Prescribing the correct dose and drug combination, which should be tailored to the individual patient, is necessary for successful treatment outcomes. A given dose may result in a wide range of blood drug concentrations as patients differ in their ability to absorb, distribute, metabolize, and excrete drugs owing to age, concurrent disease, interacting drugs, or genetic variations ${ }^{12,21-23}$ (Figure 1). Genetic polymorphisms, ${ }^{24,25}$ environmental factors, and alterations in organ function are major causes for pharmacokinetic variability and could explain why patients with uncontrolled hypertension do not respond to antihypertensive medications as expected. Measuring drug concentrations in the blood is a practical approach to account for this variability and tailor doses to individual patients.

Evidence from clinical studies regarding the range of serum drug concentration, expected to result in good therapeutic effects without intolerable adverse effects, defining the therapeutic reference range, is a prerequisite for the optimal use of TDM. True therapeutic reference ranges require supportive evidence of a relationship between drug concentrations and clinical outcomes. This is defined only for a 
limited number of drugs, and not for antihypertensive medications. However, when a therapeutic reference range is lacking, pharmacokinetic calculations, defining a dose-related reference range (DRRR), can be used. ${ }^{12,14,26}$ Based on this approach, population data on pharmacokinetic variability can be utilized to define the expected range of serum drug concentrations in patients receiving standard doses of the drug. DRRR may be used to identify non-adherent patients, as well as patients with deviant drug responses owing to pharmacokinetic abnormalities, and can reduce physician inertia by rendering treatment intensification safer for the physician, even if this implies prescribing doses outside the recommended range.

Therefore, the aims of the present study were as follows, 1) define the most commonly prescribed antihypertensive drugs in Norway and describe their pharmacokinetic characteristics, and 2) suggest serum reference ranges based on a review of authoritative literature, pharmacokinetic calculations, and drug measurements in patient samples.

\section{Material and Methods}

\section{SELECTION OF ANTIHYPERTENSIVE DRUGS, DOSE RANGES, AND DRUG}

\section{BIOTRANSFORMATION}

We searched the Norwegian Prescription Database ${ }^{4}$ for antihypertensive drugs prescribed between 2014 and 2018. The recommended low and high (initial to maximum) drug doses used for hypertension were retrieved from the Summary of Product Characteristics (SmPC) and Micromedex (https://www.micromedexsolutions.com). For each selected drug, we explored the pathways of biotransformation and drug excretion mediated by the kidney to get an overview of the main factors that can account for differences in blood levels and the need for TDM. ${ }^{27,28}$ 


\section{PUBLISHED THERAPEUTIC REFERENCE RANGES}

Data on therapeutic reference ranges were retrieved from two published reports of therapeutic and toxic drug concentrations in serum/plasma, ${ }^{29,30}$ as well as two recognized drug reference works ${ }^{28,31}$. In cases where the ranges stated by different sources failed to match, we chose those with the widest range.

\section{CALCULATION OF EXPECTED SERUM CONCENTRATIONS AND DRC FACTORS}

At steady state, the expected drug concentration at any time point in the elimination phase $\left(C_{t}\right)$ can be calculated from the dose $(D)$, the dosing interval $(d i)$, the elimination rate constant $\left(k_{e}\right)$, the time interval between drug intake and blood sampling $(\Delta t)$, the bioavailability $(F)$, and the total body clearance $(C l)^{14}$ :

$$
C t=\left[\left(\frac{D}{d i}\right) \times\left(\frac{F}{C l}\right)\right] \times\left[\frac{\left(k_{e} \times d i\right)}{\left(1-e^{-k_{e} \times d i}\right)}\right] \times\left(e^{-k_{e} \times \Delta t}\right)
$$

The concept of dose-related concentration (DRC) factors has been described by Hiemke et al ${ }^{14}$ and recently utilized in the context of evaluating antihypertensive drug adherence by Ritscher et $\mathrm{al}^{19}$. Calculation of the DRC factor is performed by omitting the dose from the equation defining the expected drug concentration, to facilitate the calculation of expected concentrations with different doses.

$$
D R C \text { factor }=\frac{C_{t}}{D}=\left[\left(\frac{1}{d i}\right) \times\left(\frac{F}{C l}\right)\right] \times\left[\frac{\left(k_{e} \times d i\right)}{\left(1-e^{-k_{e} \times d i}\right)}\right] \times\left(e^{-k_{e} \times \Delta t}\right)
$$

We calculated DRC factors and expected concentration ranges with low and high doses at $12 \mathrm{~h}\left(\mathrm{C}_{12} \mathrm{~h}\right.$; di $24, \Delta t 12)$ and $24 \mathrm{~h}\left(\mathrm{C}_{24 \mathrm{~h}} ;\right.$ di $\left.24, \Delta \mathrm{t} 24\right)$ for drugs administered once daily, and at $12 \mathrm{~h}\left(\mathrm{C}_{12 \mathrm{~h}} ; \mathrm{di} 12, \Delta \mathrm{t} 12\right)$ for drugs administered twice daily (propranolol and labetalol). Pharmacokinetic parameters were retrieved mainly from authoritative pharmacology literature..$^{32}$ In cases where these parameters could not be found in this source, we searched other reference works and drug databases,,$^{27,28,31}$ as well as primary literature regarding pharmacokinetic studies. To account for inter-individual variability in drug 
elimination, we incorporated the standard deviation of total clearance, $\mathrm{Cl} \pm \mathrm{SD}$, into equations. If the standard deviation of clearance was lacking, we applied the variance reported for the area under the curve (AUC).

Some drugs are most often administered as sustained-release formulations owing to their short half-lives (metoprolol, nifedipine, diltiazem, and doxazosin). The serum concentrations are relatively constant throughout the dosing interval as absorption is delayed, and a precisely defined elimination phase or elimination rate constant is lacking. In this case, the average concentration $\left(\mathrm{C}_{\mathrm{av}}\right)$ at steady state can be calculated, according to the formula: ${ }^{14,33}$

$$
C_{a v}=\left[\left(\frac{D}{d i}\right) \times\left(\frac{F}{C l}\right)\right]
$$

and hence,

$$
\text { DRC factor }=\left[\left(\frac{1}{d i}\right) \times\left(\frac{F}{C l}\right)\right]
$$

\section{MEASUREMENTS USING PATIENT SAMPLES}

The following patient samples were collected during 2018-2019: 1) outpatient samples from a routine TDM service ( $n=93$ ), and 2 ) inpatient samples from an ongoing study on pharmacokinetics in obese patients ( $n=63)$. The study was approved by the Regional Ethics Committees and written consents were signed and provided by patients, with the data from the TDM service approved for publication by the Data Protection Officer. We included only samples with explicitly stated information regarding the time of the last intake and time of sampling. Only concentrations at steady state collected between 12 and 24 $\mathrm{h}\left(\mathrm{C}_{12-24 \mathrm{~h}}\right)$ after the last medication intake were included. If there was any doubt regarding the validity, the samples were excluded. The parent drugs were measured, except for enalapril, ramipril, losartan, and spironolactone, in which case the active metabolites enalaprilat, ramiprilat, losartan carboxylic acid, 
and canrenone were measured. The median (range) of values for each drug is reported when measurements of three or more patient samples were available.

The serum samples were analyzed by UHPLC-MSMS at the Department of Clinical Pharmacology, St. Olav University Hospital, using a previously published and fully validated method. ${ }^{18}$ The patient samples were refrigerated after receipt at the laboratory and were analyzed consecutively within the documented stability time frame (max 3 days).

\section{ESTABLISHING SERUM REFERENCE RANGES}

We aimed to establish reference ranges that reflect expected serum concentrations with common doses used in antihypertensive treatment. To establish these reference ranges, we compared drug concentrations from I) reported authoritative literature, II) calculated $\mathrm{C}_{24 \mathrm{~h}}, \mathrm{C}_{12 \mathrm{~h}}$, and $\mathrm{C}_{\mathrm{av}}$ as explained above, and III) measurements of $\mathrm{C}_{12-24 \mathrm{~h}}$ concentrations in patient serum samples.

\section{Results}

\section{DRUG SELECTION}

Figure 2 shows the drug consumption expressed as DDD per 1000 inhabitants per year, for drug groups with blood pressure reducing effects prescribed outside hospitals in Norway during 2014-2018. ${ }^{4}$ The 12 most frequently used antihypertensive preparations in Norway during 2018, listed in order from most to least frequent, were: amlodipine, candesartan, ramipril, metoprolol, losartan, lercanidipine, losartan in combination with hydrochlorothiazide (HCT), candesartan in combination with $\mathrm{HCT}$, bumetanide, valsartan, enalapril, and furosemide. These drugs covered $75 \%$ of the total antihypertensive drug prescriptions in 2018. The loop diuretics, bumetanide and furosemide, are mainly used in heart failure and less frequently as antihypertensive therapy. They were still included in our study, together with other less often used drugs such as the aldosterone antagonists, spironolactone and eplerenone, based 
on their place in the therapy of treatment-resistant hypertension. The 26 antihypertensive drugs in Table 1 represent $97 \%$ of the antihypertensive drugs prescribed outside hospitals in Norway. Felodipine was excluded owing to analytical difficulties. Table 1 shows the involvement of metabolizing enzymes and renal excretion that can account for variabilities in serum drug concentrations of the selected 26 antihypertensive drugs.

\section{DRC FACTORS AND SERUM REFERENCE RANGES}

Table 2 shows pharmacokinetic parameters and calculated DRC factors for the selected 26

antihypertensive drugs, while Table 3 presents the suggested serum reference ranges, as well as the data used to estimate these ranges. All pharmacokinetic data retrieved from literature and the $C_{a v}, C_{12 h}, C_{24 h}$, and DRC-factor calculations are presented in detail for each drug in an Excel-file (see Excel-file, Supplemental Digital Content 1). Reference ranges were defined for all drugs, except the loop-diuretics furosemide and bumetanide, owing to extremely low expected trough concentrations for these drugs.

Owing to uncertainty whether the serum drug concentration ranges reported in the literature represent trough or $C_{\max }$ values, the emphasis was laid on the calculated concentration ranges for most drugs. For drugs dosed once daily, the range spanning from expected $C_{24 h}$ at the lowest daily dose and highest clearance (+SD) and expected $\mathrm{C}_{12 \mathrm{~h}}$ at the highest daily dose and lowest clearance (-SD) was used. For drugs administered twice daily, $\mathrm{C}_{12 \mathrm{~h}}$ values were used. For drugs administered mainly as sustainedrelease preparations, substantial consideration was given to the calculated $\mathrm{C}_{\mathrm{av}}$ ranges. Using this $\mathrm{C}_{\mathrm{av}}$ approach will tend to overestimate trough concentrations, as the pre-dose concentrations are lower than the average concentration during the dosing interval even with sustained-release formulations; we accounted for this during our estimation. To exemplify, the calculated $\mathrm{C}_{\mathrm{av}}$ range for diltiazem was 156$455 \mathrm{nmol} / \mathrm{L}$. The pre-dose concentrations are lower, and the established range was therefore adjusted to $100-500 \mathrm{nmol} / \mathrm{L}$. 
For all drugs, we assumed linear pharmacokinetics throughout the therapeutic dose range. For lercanidipine, we adjusted for increasing bioavailability with increasing dose. ${ }^{34}$ If drug clearances for different age groups were reported in the literature, the clearance determined in the elderly was used.

The established serum reference range was solely based on calculations for labetalol, telmisartan, bendroflumethiazide, canrenone, and eplerenone, as shown in Table 3. For the other listed drugs, the limited numbers of patient samples were used as validation to determine whether measured serum concentrations would fit the calculated ranges, and we made some minor adjustments to the ranges when the measured samples failed to comply with the calculations. We considered the range of measured values or, if the number of measurements was large enough, the $10-90^{\text {th }}$ percentile range, with emphasis on the median value. To exemplify, the calculated range for candesartan was 20-289 $\mathrm{nmol} / \mathrm{L}$. From the patient samples, one low concentration (12 nmol/L; dose: $8 \mathrm{mg}$ ) was observed. The lower limit was adjusted based on this low patient sample and the $10^{\text {th }}$ percentile $(16 \mathrm{nmol} / \mathrm{L})$. The upper limit was reduced after evaluating $C_{12 h}$ values from inpatients who participated in the obesity study (170$180 \mathrm{nmol} / \mathrm{L})$ and the $90^{\text {th }}$ percentile $(111 \mathrm{nmol} / \mathrm{L})$. Therefore, the established reference range was adjusted to $15-200 \mathrm{nmol} / \mathrm{L}$. For metoprolol, the calculated range was $39-235 \mathrm{nmol} / \mathrm{L}$; based on patient samples and the $10-90^{\text {th }}$ percentile range $(19-542 \mathrm{nmol} / \mathrm{L})$, we adjusted the established range to $10-500$ $\mathrm{nmol} / \mathrm{L}$. For losartan carboxylic acid, the established range was based on the high calculated upper limit (31-374 nmol/L), despite the low concentrations from limited patient samples ( $\mathrm{n}=5,48(35-73) \mathrm{nmol} / \mathrm{L})$, after evaluating high $\mathrm{C}_{12 \mathrm{~h}}$ values from inpatients in the obesity study $(166-256 \mathrm{nmol} / \mathrm{L})$. Therefore, the established reference range for losartan carboxylic acid was kept close to the calculated value, 30-350 $\mathrm{nmol} / \mathrm{L}$.

We excluded samples from patients with suspected non-adherence (negative results or information on >24 h sampling time) or extensive individual variability (i.e. renal failure, CYP polymorphism). 
Of the 24 drugs listed in Table 3, only amlodipine demonstrated an established serum reference range corresponding with the literature.

\section{Discussion}

We proposed the serum concentration reference ranges for 24 antihypertensive drugs, reflecting expected concentration ranges in patients using commonly prescribed doses, with samples drawn 12-24

$\mathrm{h}$ after the last drug intake. We anticipate that this broad definition of proper sampling time, $12-24 \mathrm{~h}$ after drug intake regardless of once or twice daily dosing, which admittedly gives somewhat wider reference ranges, is a pragmatic approach to making TDM of antihypertensives a practical tool for prescribing doctors. This was chosen to simplify the recommendations to physicians, and to allow for sampling within normal office hours irrespective of morning or evening administration, especially as drug administration in the evening could become increasingly common with the recent focus on chronotherapy. ${ }^{14}$ The reference ranges are based on calculations from known pharmacokinetic properties of drugs, and for some drugs have been validated against a limited number of drug measurements in patient samples. The reference ranges have not been correlated to drug responses and are thus not to be considered as therapeutic reference ranges. We emphasize that measurements of serum concentrations and comparison to our proposed reference ranges must be interpreted in light of clinical findings, including standardized blood pressure recordings ${ }^{35}$ and other signs and symptoms.

Persistent hypertension leads to serious end-organ damage if left untreated, ${ }^{1}$ with high costs to the individual and society. The use of serum drug concentrations to detect non-adherence and optimize treatment could improve treatment outcomes and reduce costs. The European guidelines of arterial hypertension $^{1}$ and the American Heart Association's scientific statement on the detection, evaluation, and management of resistant hypertension ${ }^{36}$ focus on uncontrolled hypertension, drug-resistant hypertension, drug non-adherence, and suboptimal drug dosing, emphasizing the need for personalized 
antihypertensive treatment. The goal of TDM is to optimize the pharmacological treatment of the patient by individualization of the dosing regimen based on the measured serum drug concentration. ${ }^{13}$

\section{INTERPRETATION OF SERUM ANTIHYPERTENSIVE DRUG CONCENTRATION MEASUREMENTS}

As shown in Table 1, several antihypertensive drugs are metabolized by cytochrome P450 (CYP)

enzymes, and elimination may depend on the liver and/or kidney functions. Thus, polymorphisms of

genes, organ failure, and drug-drug interactions can alter the serum drug concentrations in the individual patient (Figure 1). As hypertension is a common disease and approximately half the patients fail to reach the treatment goal, using serum drug concentrations and the established reference ranges could be an objective tool to the physician to uncover non-adherence, determine the most suitable drug, and achieve the correct dose when deviant drug responses owing to pharmacokinetic abnormalities appear. Furthermore, TDM may reduce physician's inertia by rendering treatment intensification safer for the physician.

Undetectable drug concentrations in the serum suggest non-adherence, whereas detectable values below the lower limit of the established serum reference range most likely reflect partial drug adherence. Additionally, it has been reported that the lower limit of DRRR can be used to evaluate adherence. ${ }^{17,19}$ The treating physician should be careful to avoid accusations of non-adherence in a confrontational manner, as this may alienate the patient and damage the physician-patient relationship. Instead, the reason for the unexpectedly low or absent drug concentration should be explored along with the patient in a compassionate manner, ${ }^{20}$ with the common goal to find a suitable and efficient treatment. Moreover, one should take into consideration the possibility of rare causes of low drug levels, including CYP2D6 ultra-rapid metabolism owing to gene amplification, or the concomitant use of enzyme-inducing agents such as certain antiepileptic drugs, rifampicin, or St. John's Wort. Before assuming non-adherence, the treating physician should also ascertain that the measurement method 
used has adequate analytical sensitivity (lower limit of quantification in regards to clinical reference ranges). ${ }^{37}$ This is especially relevant with certain antihypertensive drugs presenting low expected trough concentrations such as lercanidipine. Loop diuretics, bumetanide and furosemide, demonstrate extremely low trough concentrations, and therefore, are not expected to be present at detectable levels in trough samples.

$\mathrm{A} \mathrm{C}_{12-24 \mathrm{~h}}$ concentration within the reference range is consistent with adherence to therapy, and therapeutic effects may be expected. However, considerable inter-individual variabilities can be observed in the dose-concentration-response relationship. In patients showing an insufficient therapeutic response, concentrations in the low end of the reference range may suggest either partial non-adherence or individual pharmacokinetic factors that cause rapid elimination. A lack of effect despite concentrations in the higher end of the reference range is indicative of true drug non-response, in which case a diagnostic re-evaluation and switching or adding drugs could be in order.

At therapeutic doses, $\mathrm{C}_{12-24 \mathrm{~h}}$ concentrations above the reference range may suggest impaired elimination, and dose reduction should be considered, especially if the patient experiences adverse effects. Impaired renal function or other organ dysfunction, drug-drug interactions causing CYP enzyme inhibition, or slow metabolism owing to genetic polymorphisms could be deemed possible mechanisms. Furthermore, concentrations well above the expected ranges may indicate overdosing or intoxication, although certain drugs such as valsartan and irbesartan demonstrate an extremely high amplitude between $C_{\max }$ and $C_{\min }$, so adequate sampling time should always be ascertained in case of a high measurement.

\section{URINE OR SERUM TO EVALUATE DRUG ADHERENCE?}

Urine has been suggested as the medium of choice to detect drug non-adherence owing to the longer time window available for drug detection than in serum. ${ }^{38-41}$ However, this may lead to overestimation of drug adherence, as some drugs may be present in urine for several days after the last dose. Furthermore, 
not all antihypertensive drugs or their metabolites are excreted in the urine. For instance, telmisartan is excreted unchanged in the feces ${ }^{42,43}$ (Table 1). The excretion pattern of a drug, or drug metabolites, in urine with time is not extensively investigated for all the drugs, which makes the interpretation difficult and may lead to false assessments of drug adherence. Furthermore, urine measurements may only be used as a qualitative assessment of adherence, but cannot be used to assess drug response, which is possible with serum quantification. This implies that the measurement of serum concentrations, in contrast to urine analysis, could be a tool for personalized medicine.

\section{LIMITATIONS}

Our data relied, for the most part, on theoretical calculations based on known pharmacokinetic properties of the different drugs and were not extensively validated against measured serum drug concentrations in patient samples. We retrieved the pharmacokinetic variables from authoritative sources; however, the quality and representativity (i.e. age and co-morbidity of included study subjects) of the underlying pharmacokinetic studies may vary. Drug clearance in the elderly was used if available, as most patients treated with antihypertensive drugs are older than 50 years. ${ }^{4}$ Renal clearance in the elderly can be reduced both by age and disease (see Table 1). ${ }^{44,45}$ By incorporating 1 SD of total clearance to account for inter-individual variability, the resulting reference ranges should, in theory, comprise $68 \%$ of the serum concentrations in a patient population. In practice, they will encompass a larger percentage, as it is likely that frail, sick, or old patients with low clearances are prescribed low doses and, likewise, comparatively healthy and young patients with high clearances are prescribed higher doses. Nonetheless, the total clearance variability in the patient population varies more than that accounted for by our reference ranges. Therefore, reference ranges should be used cautiously, and we expect that several of the suggested ranges will have to be adjusted according to experiences with clinical applications. 
To utilize serum concentration reference ranges for dose optimization, one must assume that there exists a relationship between dose, serum concentrations, and responses of selected drugs. We assumed the pharmacokinetics of the drugs to be linear. However, the relationship between serum concentration and effect is known to be more complex for some drugs. For instance, the serum concentration of betablockers demonstrates a linear relationship with heart rate but not with the BP-lowering effect. ${ }^{46}$ The correlation is also poorly documented in the case of polypharmacy, which often is the reality in patients with hypertension. The 2018 ESH/ESC Guidelines ${ }^{1}$ recommend the use of combinations of two antihypertensive drugs, an ACEI or ARB together with a thiazide diuretic or $C C B$, in a single pill as initial therapy, to achieve a blood pressure target in most patients of $<130 / 80 \mathrm{mmHg}$. Further studies are needed to comprehensively investigate the association between serum drug concentration and clinical responses in hypertensive patients to confirm the clinical relevance of our established serum concentration ranges.

When deciding on the reference range for each drug, we observed that for most drugs we could not emphasize the serum concentration ranges presented in authoritative literature, as the sources of these ranges suggest that they often represent $C_{\max }$ values. According to standard accepted TDM routines, blood samples should be collected at steady-state and at the end of the dosing interval (trough concentration $\left./ \mathrm{C}_{24}\right) \cdot{ }^{32}$ For most drugs, steady-state is reached in approximately 3 days, except for amlodipine, which has a long half-life. Real trough samples can be difficult to collect in daily routine. Our broader definition of proper sampling time, $12-24 \mathrm{~h}$ after the last intake, will render the reference ranges more applicable to real-world sampling practices; however, allowing for sampling at $12 \mathrm{~h}$ results in considerably higher upper limits of the reference range.

Furthermore, several antihypertensive drugs may be used for other indications like heart failure, arrhythmias, and migraines. Recommended dose ranges for other indications may differ from those in 
hypertension (Table 3), and pharmacokinetics may be altered in, for instance, heart failure when compared with hypertensive patients. Thus, the established reference ranges must be used with caution for other indications. In patients using doses outside the recommended dose range for hypertension, the physician can calculate the expected serum drug concentration for a given patient by multiplying the DRC factors with the daily dose, paying attention to the di and $\Delta t$.

In conclusion, the proposed reference ranges for antihypertensive drugs can be used to interpret serum drug concentration measurements in hypertensive patients and could be an objective tool to assess adherence, to optimize dosing by facilitating drug titration to higher doses, or suggest the need for combination treatment, or to detect deviant drug responses owing to pharmacokinetic abnormalities that may require alternate drugs, thereby, improving pharmacotherapy in hypertensive patients. 
TABLE 1. Metabolism and excretion of antihypertensive drugs

The table shows the involvement of metabolizing enzymes and renal excretion of commonly used antihypertensive drugs, suggesting that CYP polymorphisms and renal failure might alter serum drug concentrations.

\begin{tabular}{|c|c|c|c|c|}
\hline Drug & $\begin{array}{l}\text { Metabolic elimination (minor } \\
\text { pathways in brackets) }\end{array}$ & $\begin{array}{l}\text { Renal excretion of } \\
\text { parent drug (\%) }\end{array}$ & $\begin{array}{l}\text { Renal excretion of } \\
\text { metabolites (\%) }\end{array}$ & References \\
\hline \multicolumn{5}{|l|}{ Alpha-blockers } \\
\hline Doxazosin^^ & CYP $3 A 4$ (2D6, 2C9) & none & 9 & 28,47 \\
\hline \multicolumn{5}{|l|}{ Beta-blockers } \\
\hline Atenolol & None & 50 & none & 28,47 \\
\hline Bisoprolol & CYP 2D6 (3A4) & $50-60$ & 50 & $10,28,32,47,48$ \\
\hline Carvedilo|^ & CYP 2D6, 2 C9 (3A4, 2C19, 1A2, 2E1) & $<1$ & 16 & 28,47 \\
\hline Labetalol & Conjugation & 5 & $55-60$ & $28,32,47,49$ \\
\hline Metoprolol & CYP 2D6 & 5 & 95 & $28,47,49,50$ \\
\hline Propranolol^ & CYP 2D6 (1A2) & $<1$ & 99 & 47,50 \\
\hline \multicolumn{5}{|l|}{ CCBs } \\
\hline Amlodipine & CYP 3A4/5 & 10 & 60 & 47,50 \\
\hline Diltiazem $^{\wedge}$ & CYP $3 A 4$ (2D6) & $2-4$ & $35-50$ & $28,32,47,51,52$ \\
\hline Lercanidipine & CYP $3 A 4$ & none & 50 & 27,49 \\
\hline Nifedipine & CYP $3 A 4$ & $<0,1$ & 80 & 28,49 \\
\hline Verapamil^ & CYP $3 A 4(1 \mathrm{~A} 2,2 \mathrm{C} 8,2 \mathrm{C} 19,2 \mathrm{C} 18)$ & $3-4$ & 70 & 28,49 \\
\hline \multicolumn{5}{|l|}{ ACEls } \\
\hline Enalapril (prodrug) & Carboxylesterase & 18 & $44 \%$ & $27,47,49$ \\
\hline Lisinopril & None & 100 & none & $28,32,49$ \\
\hline Ramipril (prodrug) & Carboxylesterase & $<2$ & $60 \%$ & 28 \\
\hline \multicolumn{5}{|l|}{ ARBs } \\
\hline Candesartan & CYP 2C9 (minor pathway) & 26 & 7 & $10,27,47$ \\
\hline Irbesartan & Conjugation (2C9 $10 \%)$ & $<2$ & & $10,27,47,49$ \\
\hline Losartan^ & CYP (2C9, 3A4 $14 \%)$ & 4 & 6 & $27,32,47$ \\
\hline Telmisartan & Conjugation & none & $<1 \%$ & $32,43,47$ \\
\hline Valsartan & CYP 2C9 (minor pathway) & 13 & none & $28,47,53$ \\
\hline \multicolumn{5}{|l|}{ Thiazide diuretics } \\
\hline Bendroflumethiazide & 70\% (unknown enzymes) & 30 & & 49,54 \\
\hline Hydrochlorothiazide & None & $60-100$ & & $10,32,47$ \\
\hline \multicolumn{5}{|l|}{ Loop diuretics } \\
\hline Bumetanide & Conjugation (40\%) & 45 & 36 & $28,47,49$ \\
\hline Furosemide & Conjugation (10-35\%) & $60-90$ & & 28,49 \\
\hline \multicolumn{5}{|c|}{ Potassium-sparing diuretics } \\
\hline Spironolactone ${ }^{\wedge}$ & Unknown enzymes & none & $47-57$ & 28,49 \\
\hline Eplerenone & CYP $3 A 4$ & $<5 \%$ & 67 & 28,47 \\
\hline $\begin{array}{l}\text { ^Bioactive metabolites } \\
\text { CYP: Cytochrome P450 enzy } \\
\text { CCBs: calcium channel block }\end{array}$ & $\begin{array}{l}\text { nes } \\
r \text {, ACEIs: angiotensin converting enzym }\end{array}$ & nointer & eceptor blockers & \\
\hline
\end{tabular}


TABLE 2. Pharmacokinetic properties used to calculate dose-related concentration (DRC) factors and expected serum concentration ranges (shown in TABLE 3 ). Low and high DRC factors may be multiplied with a patient's individual dose to yield the expected trough serum concentration interval using the given di and $\Delta t$.

\begin{tabular}{|c|c|c|c|c|c|c|c|}
\hline Drug & di and $\Delta t[h]$ & $\mathbf{F}$ & $\mathrm{Cl} \pm \mathrm{SD}[\mathrm{mL} / \mathrm{min}]$ & $\mathbf{t}_{1 / 2}[\mathrm{~h}]$ & $\begin{array}{l}\text { Low DRC factor } \\
{[(\mathrm{nmol} / \mathrm{L}) / \mathrm{mg}]}\end{array}$ & $\begin{array}{l}\text { High DRC factor } \\
{[(\mathrm{nmol} / \mathrm{L}) / \mathrm{mg}]}\end{array}$ & References \\
\hline \multicolumn{8}{|l|}{ Alpha-blockers } \\
\hline Doxazosin & 24 & 0.35 & $158 \pm 99$ & 19 & 1.31 & 5.71 & 32 \\
\hline \multicolumn{8}{|l|}{ Beta-blockers } \\
\hline Atenolol & 24 & 0.58 & $168 \pm 21$ & 6.1 & 1.53 & 1.96 & 32 \\
\hline Bisoprolol & 24 & 0.90 & $250 \pm 54$ & 11 & 2.70 & 4.19 & 27,28 \\
\hline Carvedilol & 24 & 0.30 & $609 \pm 119$ & 8 & 0.21 & 0.31 & 31,32 \\
\hline Labetalol & 12 & 0.25 & $1610 \pm 371$ & 7 & $0.28+$ & $0.44 \dagger$ & 32 \\
\hline Metoprolol & 24 & 0.38 & $1050 \pm 210$ & 3.5 & $0.78 \ddagger$ & $1.17 \ddagger$ & $27,28,32$ \\
\hline Propranolol & 12 & 0.46 & $1120 \pm 350$ & 5 & $0.65+$ & $1.24 \dagger$ & 32 \\
\hline \multicolumn{8}{|l|}{ CCBs } \\
\hline Amlodipine & 24 & 0.74 & $413 \pm 105$ & 39 & 1.95 & 3.27 & 32 \\
\hline Diltiazem & 24 & 0.38 & $826 \pm 154$ & 7.5 & $0.65 \ddagger$ & $0.95 \ddagger$ & $27,28,32$ \\
\hline Lercanidipine & 24 & $0.10^{\wedge}$ & $1283 \pm 45$ & 9 & 0.023 & 0.095 & 55 \\
\hline Nifedipine & 24 & 0.50 & $490 \pm 126$ & 8.5 & $1.63 \ddagger$ & $2.75 \ddagger$ & 31,32 \\
\hline Verapamil & 24 & 0.35 & $1050 \pm 420$ & 12 & $0.36 \ddagger$ & $0.85 \ddagger$ & 32 \\
\hline \multicolumn{8}{|l|}{ ACEls } \\
\hline Enalaprilat & 24 & 0.41 & $141 \pm 43$ & 11 & 1.72 & 3.23 & 32 \\
\hline Lisinopril & 24 & 0.25 & $106 \pm 13$ & 12 & 1.66 & 2.13 & 31,56 \\
\hline Ramiprilat & 24 & 0.48 & $203 \pm 57$ & 14 & 1.72 & 3.06 & 57 \\
\hline \multicolumn{8}{|l|}{ ARBs } \\
\hline Candesartan & 24 & 0.14 & $25.9 *$ & 9.7 & 2.52 & 3.83 & 27,58 \\
\hline Irbesartan & 24 & 0.70 & $148 \pm 38$ & 13 & 3.01 & 5.08 & 32 \\
\hline Losartan carboxylic acid & 24 & 0.14 & $47 \pm 5.8$ & 5.4 & 0.63 & 0.80 & 59 \\
\hline Telmisartan & 24 & 0.42 & $800 \pm 250$ & 24 & 0.37 & 0.71 & 43 \\
\hline Valsartan & 24 & 0.23 & $34.3 \pm 6.3$ & 9.4 & 3.28 & 4.76 & 32 \\
\hline \multicolumn{8}{|l|}{ Thiazide diuretics } \\
\hline Bendroflumethiazide & 24 & 1 & $374 \pm 101$ & 9 & 1.20 & 2.09 & 28,54 \\
\hline Hydrochlorothiazide & 24 & 0.71 & $343 \pm 77$ & 8 & 1.17 & 1.85 & 32 \\
\hline \multicolumn{8}{|l|}{ Loop diuretics } \\
\hline Bumetanide & 24 & 1 & $126 \pm 21$ & 1 & $* *$ & $* *$ & 60 \\
\hline Furosemide & 24 & 0.71 & $116 \pm 41$ & 1.3 & $* *$ & $* *$ & 32 \\
\hline \multicolumn{8}{|l|}{ Potassium-sparing diuretics } \\
\hline Canrenone & 24 & 0.25 & $301 \pm 130$ & 16.1 & 0.68 & 1.70 & 61 \\
\hline Eplerenone & 24 & 0.69 & $121 \pm 62$ & 3 & 0.14 & 0.43 & 62 \\
\hline
\end{tabular}

*No data available for SD. Range (21.7-32.9) $\mathrm{ml} / \mathrm{min}$ used in the calculation of DRC factor

**DRC factors not calculated due to short half-life that causes very low trough concentrations (pmol/L)

tDRC factors calculated assuming the use of depot formulations

^Bioavailability increases to 0.20 with higher doses $(20 \mathrm{mg})$, which is used for the high DRC factor calculation

di: dosing interval; $\triangle \mathrm{t}$ : sampling interval; F: bioavailability; Cl: total clearance; SD: standard deviation; t1/2: drug elimination half-life; CCBs: calcium channel blockers, ACEls: angiotensin-converting enzyme inhibitors, ARBs: angiotensin II receptor blockers 
TABLE 3. Established serum reference ranges of antihypertensive drugs

\begin{tabular}{|c|c|c|c|c|c|c|c|}
\hline & \multirow{2}{*}{$\begin{array}{l}\text { Dose (mg) } \\
\text { low-high }\end{array}$} & \multirow{2}{*}{$\begin{array}{l}\text { I Serum } \\
\text { concentrations } \\
\text { from literature } \\
\text { (nmol/L) } ¥\end{array}$} & \multicolumn{3}{|c|}{ II Calculated concentrations ( $\mathrm{nmol} / \mathrm{L}$ ) } & \multirow{2}{*}{$\begin{array}{l}\text { III } C_{12-24 h} \text { patient samples (nmol/L) } \\
\text { Median (range) }\end{array}$} & \multirow{2}{*}{$\begin{array}{l}\text { Established } \\
\mathrm{C}_{12-24 \mathrm{~h}} \text { serum } \\
\text { concentration } \\
\text { range (nmol/L) }\end{array}$} \\
\hline & & & $\mathrm{C}_{24 \mathrm{~h}^{\wedge}}$ & $\mathrm{C}_{12 \mathrm{~h}^{\wedge}}$ & $\mathrm{Cav}^{\wedge}$ & & \\
\hline \multicolumn{8}{|l|}{ Alpha-blockers } \\
\hline Doxazosin (depot) & $4-8$ & $22-332$ & $5.2-46$ & 8.1-71 & 8.4-73 & $n=328(18-80)$ & $5-80$ \\
\hline \multicolumn{8}{|l|}{ Beta-blockers } \\
\hline Atenolol & $50-100$ & $375-3755$ & $76-196$ & $299-768$ & $400-1029$ & $\mathrm{n}=1(228)$ & 75-750 \\
\hline Bisoprolol & $5-20$ & $31-307$ & $14-84$ & $29-178$ & $32-196$ & $\mathrm{n}=5 \quad 22(10-137)$ & $10-200$ \\
\hline Carvedilol & $12.5-50$ & 49-369 & $2.6-16$ & 7.4-44 & $8.8-52$ & $n=3 \quad 9(8-176)$ & $2,5-50$ \\
\hline Labetalol & $200-2400$ & $76-609$ & n.a.* & $56-1067$ & $107-2048$ & - & $50-1000$ \\
\hline Metoprolol (depot) & $50-200$ & $30-2244$ & $1.6-9.7$ & 17-105 & $39-235^{* *}$ & $n=34109(8-702)$ & $10-500$ \\
\hline Propranolol & $80-320$ & $77-3470$ & n.a.* & $52-398$ & $134-1024$ & $n=2(52-146)$ & $50-400$ \\
\hline \multicolumn{8}{|l|}{ CCBs } \\
\hline Amlodipine & $5-10$ & $7,3-37$ & $9.7-33$ & $12-40$ & $12-41$ & $n=2126(9.7-61.8)$ & $10-40$ \\
\hline Diltiazem (depot) & $240-480$ & $73-965$ & $42-123$ & $128-373$ & $156-455^{* *}$ & $n=1(303)$ & $100-500$ \\
\hline Lercanidipine ${ }^{\dagger}$ & $10-20$ & No data & $0.23-1.9$ & $0.57-4.8$ & $0.65-5.5$ & $n=5 \quad 0.7(0.28-1.52)$ & $0.2-5$ \\
\hline Nifedipine (depot) & $20-60$ & $58-433$ & $10-53$ & $28-142$ & $33-165 * *$ & $n=5 \quad 104(31-212)$ & $20-150$ \\
\hline Verapamil (depot) & $120-480$ & $44-1100$ & $20-188$ & $40-376$ & $44-407$ & $n=2(32-500)$ & $40-400$ \\
\hline \multicolumn{8}{|l|}{ ACEIs } \\
\hline Enalaprilat & $5-40$ & $26-130$ & $8.6-129$ & $18-275$ & $20-302$ & $n=2(14-21)$ & $10-300$ \\
\hline Lisinopril & $5-80$ & $2,5-173$ & $8.3-170$ & $17-340$ & $18-368$ & $n=2(10-37.9)$ & $10-300$ \\
\hline Ramiprilat & $2.5-10$ & $2,6-103$ & $4.3-31$ & $7.8-55$ & 8.3-59 & $n=8 \quad 8(4-19)$ & $4-60$ \\
\hline \multicolumn{8}{|l|}{ ARBs } \\
\hline Candesartan & $8-32$ & $182-409$ & $20-122$ & $48-289$ & $54-325$ & $n=2238(12-166)$ & $15-200$ \\
\hline Irbesartan & $150-300$ & $4434-7701$ & $451-1525$ & $855-2893$ & $915-3094$ & $n=5 \quad 357(107-586)$ & $300-3000$ \\
\hline Losartan carboxylic acid & $50-100$ & $(458-1488)$ & $31-80$ & $146-374$ & $211-540$ & $n=5 \quad 48(35-73)$ & $30-350$ \\
\hline Telmisartan & $20-80$ & $25-225$ & $7.5-57$ & $11-81$ & $11-82$ & - & $8-80$ \\
\hline Valsartan & $80-320$ & $1837-13777$ & $263-1523$ & $636-3691$ & $723-4191$ & $n=11952(359-1891)$ & $300-4000$ \\
\hline \multicolumn{8}{|l|}{ Thiazide diuretics } \\
\hline Bendroflumethiazide & $1.25-5$ & $119-235$ & $1.5-10$ & $3.8-26$ & $4.3-30$ & - & $1.5-30$ \\
\hline Hydrochlorothiazide & $12.5-50$ & $61-122$ & $15-92$ & $41-262$ & $49-311$ & $n=2645$ (19-149) & $15-300$ \\
\hline \multicolumn{8}{|l|}{ Potassium-sparing diuretics } \\
\hline Canrenone & $25-100$ & $147-206$ & $17-170$ & $28-285$ & $30-298$ & $\mathrm{n}=2(27-89)$ & $15-300$ \\
\hline Eplerenone & $25-50$ & No data & $3.4-21$ & $55-341$ & $158-980$ & - & $3.5-350$ \\
\hline $\begin{array}{l}{ }^{\wedge} \mathrm{C}_{24}=\text { minimum concentration } \\
* \text { Dosing interval usually } 12 \mathrm{~h} \\
{ }^{* *} \mathrm{C}_{\mathrm{av}} \text { is a better predictor of } \mathrm{C}_{1} \\
* * * \text { Most likely refers to the par } \\
+ \text { Bioavailability increases to } 0.2 \\
\text { † For references see materials a } \\
\text { CCBs: calcium channel blockers, }\end{array}$ & $\begin{array}{l}\text { ough) at } 24 \mathrm{~h} \\
\text { it serum conc } \\
\text { with higher do } \\
\text { I methods } \\
\text { CEls: angioten }\end{array}$ & $\begin{array}{l}C_{12 h}=\text { concentratior } \\
\text { vhen using depot fo } \\
\text { ting enzyme inhibitc }\end{array}$ & $\begin{array}{l}12 \mathrm{~h} \text { post-do } \\
\text { Alation } \\
\text { alculating the } \\
\text { ARBs: angiot }\end{array}$ & $\begin{array}{l}\text { pper range of } \\
\text { in II receptor }\end{array}$ & $\begin{array}{l}\text { le calculated } \\
\text { lockers }\end{array}$ & ncentrations & \\
\hline
\end{tabular}




\section{References}

1. Williams B, Mancia G, Spiering W, et al. 2018 ESC/ESH Guidelines for the management of arterial hypertension: The Task Force for the management of arterial hypertension of the European Society of Cardiology and the European Society of Hypertension. Blood Press. 2018;27:314-340.

2. Kearney PM, Whelton M, Reynolds K, Whelton PK, He J. Worldwide prevalence of hypertension: a systematic review. J Hypertens. 2004;22(1):11-19.

3. Ezzati M, Lopez AD, Rodgers A, Vander Hoorn S, Murray CJ. Selected major risk factors and global and regional burden of disease. Lancet. 2002;360(9343):1347-1360.

4. Norwegian Institute of Public Health (NIPH). https://www.fhi.no/en/hn/health-registries/norpd/. Accessed March 30, 2020.

5. Chow CK, Teo KK, Rangarajan S, et al. Prevalence, awareness, treatment, and control of hypertension in rural and urban communities in high-, middle-, and low-income countries. JAMA. 2013;310(9):959-968.

6. Calhoun DA, Jones D, Textor S, et al. Resistant hypertension: diagnosis, evaluation, and treatment: a scientific statement from the American Heart Association Professional Education Committee of the Council for High Blood Pressure Research. Circulation. 2008;117(25):e510-526.

7. Eskas PA, Heimark S, Mariampillai JE, Larstorp AC, Fadl Elmula FE, Hoieggen A. Adherence to medication and drug monitoring in apparent treatment-resistant hypertension. Blood Press. 2016;25:199-205.

8. Hamdidouche I, Jullien V, Boutouyrie P, Billaud E, Azizi M, Laurent S. Routine urinary detection of antihypertensive drugs for systematic evaluation of adherence to treatment in hypertensive patients. J Hypertens. 2017;35(9):1891-1898.

9. Kjeldsen SE, Julius S, Dahlöf B, Weber MA. Physician (investigator) inertia in apparent treatmentresistant hypertension - insights from large randomized clinical trials. Lennart Hansson Memorial Lecture. Blood Press. 2015;24(1):1-6.

10. Berra E, Azizi M, Capron A, et al. Evaluation of adherence should become an integral part of assessment of patients with apparently treatment-resistant hypertension. Hypertension. 2016;68(2):297-306.

11. Ceral J, Habrdova V, Vorisek V, Bima M, Pelouch R, Solar M. Difficult-to-control arterial hypertension or uncooperative patients? The assessment of serum antihypertensive drug levels to differentiate non-responsiveness from non-adherence to recommended therapy. Hypertens Res. 2011;34(1):87-90.

12. Aronson JK, Hardman M. ABC of monitoring drug therapy. Measuring plasma drug concentrations. BMJ. 1992;305(6861):1078-1080.

13. Kang JS, Lee MH. Overview of therapeutic drug monitoring. Korean J Intern Med. 2009;24(1):110. 
14. Hiemke C, Bergemann N, Clement HW, et al. Consensus Guidelines for Therapeutic Drug Monitoring in Neuropsychopharmacology: Update 2017. Pharmacopsychiatry. 2018;51(1-02):e1.

15. De Nicolo A, Avataneo V, Rabbia F, et al. UHPLC-MS/MS method with protein precipitation extraction for the simultaneous quantification of ten antihypertensive drugs in human plasma from resistant hypertensive patients. J Pharm Biomed Anal. 2016;129:535-541.

16. Kristoffersen L, Oiestad EL, Opdal MS, Krogh M, Lundanes E, Christophersen AS. Simultaneous determination of 6 beta-blockers, 3 calcium-channel antagonists, 4 angiotensin-II antagonists and 1 antiarrhythmic drug in post-mortem whole blood by automated solid phase extraction and liquid chromatography mass spectrometry. Method development and robustness testing by experimental design. J Chromatogr B Analyt Technol Biomed Life Sci. 2007;850(1-2):147-160.

17. Punt AM, Stienstra NA, van Kleef MEA, et al. Screening of cardiovascular agents in plasma with LC-MS/MS: A valuable tool for objective drug adherence assessment. J Chromatogr B Analyt Technol Biomed Life Sci. 2019;1121:103-110.

18. Gundersen POM, Helland A, Spigset O, Hegstad S. Quantification of 21 antihypertensive drugs in serum using UHPLC-MS/MS. J Chromatogr B Analyt Technol Biomed Life Sci. 2018;1089:84-93.

19. Ritscher S, Hoyer M, Wunder C, Obermuller N, Toennes SW. Evaluation of the dose-related concentration approach in therapeutic drug monitoring of diuretics and beta-blockers - drug classes with low adherence in antihypertensive therapy. Sci Rep. 2019;9(1):15652.

20. Brinker S, Pandey A, Ayers $\mathrm{C}$, et al. Therapeutic drug monitoring facilitates blood pressure control in resistant hypertension. J Am Coll Cardiol. 2014;63(8):834-835.

21. Doogue MP, Polasek TM. The ABCD of clinical pharmacokinetics. Ther Adv Drug Saf. 2013;4(1):57.

22. Meyer UA, Zanger UM, Schwab M. Omics and drug response. Annu Rev Pharmacol Toxicol. 2013;53:475-502.

23. Bengtsson F. Therapeutic drug monitoring of psychotropic drugs. TDM "nouveau". Ther Drug Monit. 2004;26(2):145-151.

24. Oliveira-Paula GH, Pereira SC, Tanus-Santos JE, Lacchini R. Pharmacogenomics and hypertension: current insights. Pharmgenomics Pers Med. 2019;12:341-359.

25. Weeke P, Roden DM. Applied pharmacogenomics in cardiovascular medicine. Annu Rev Med. 2014;65:81-94.

26. Patsalos PN, Berry DJ, Bourgeois BF, et al. Antiepileptic drugs-best practice guidelines for therapeutic drug monitoring: a position paper by the subcommission on therapeutic drug monitoring, ILAE Commission on Therapeutic Strategies. Epilepsia. 2008;49(7):1239-1276.

27. Summary of Product Characteristics (SPC). The Norwegian Medicine Agency (NoMA) medicine database («legemiddelsøk»). https://www.legemiddelsok.no/. Accessed August 14, 2019. 
28. IBM Micromedex ${ }^{\circledR}$ DRUGDEX $^{\circledR}$ : IBM Watson Health, Greenwood Village, Colorado, USA. https://www.micromedexsolutions.com. Accessed August 8, 2019.

29. Repetto MR, Repetto M. Therapeutic, toxic, and lethal concentrations in human fluids of 90 drugs affecting the cardiovascular and hematopoietic systems. J Toxicol Clin Toxicol. 1997;35(4):345-351.

30. Schulz M, Iwersen-Bergmann S, Andresen $H$, Schmoldt A. Therapeutic and toxic blood concentrations of nearly 1,000 drugs and other xenobiotics. Crit Care. 2012;16(4):R136.

31. Widdop B, Watts, Jo, Moffat, Anthony C., Osselton, M. David. Clarke's Analysis of Drugs and Poisons : In Pharmaceuticals, Body Fluids and Postmortem Material. Vol Fourth edition2011.

32. Brunton LL, Chabner BA, Knollmann BC. Goodman \& Gilman's The Pharmacological Basis of Therapeutics 12th ed: McGraw-Hill Education - Europe; 2010.

33. Rowland M, Tozer TN. Clinical Pharmacokinetics and Pharmacodynamics: Concepts and Applications. 4th ed: Lippincott Williams And Wilkins 2010.

34. Summary of Product Characteristics (SPC) - Lercanidipine. The Norwegian Medicine Agency (NoMA) medicine database ( «legemiddels $\varnothing k »)$. https://www.legemiddelsok.no/sider/Legemiddelvisning.aspx?pakningld=2c85ee6f-ec32-46c3b3bd-e5d8510536dd\&f=Han;Mar;par;gen\&searchquery=Lerkanidipin Accessed March 30, 2020.

35. O'Brien E, Dolan E, Stergiou GS. Achieving reliable blood pressure measurements in clinical practice: It's time to meet the challenge. J Clin Hypertens (Greenwich). 2018;20(7):1084-1088.

36. Carey RM, Calhoun DA, Bakris GL, et al. Resistant hypertension: detection, evaluation, and management: a scientific statement from the American Heart Association. Hypertension. 2018;72(5):e53-e90.

37. Bioanalytical Method Validation - Guidance for Industry. Food and Drug Administration (FDA). 05/24/2018; https://www.fda.gov/regulatory-information/search-fda-guidancedocuments/bioanalytical-method-validation-guidance-industry.

38. Jung $\mathrm{O}$, Gechter JL, Wunder C, et al. Resistant hypertension? Assessment of adherence by toxicological urine analysis. J Hypertens. 2013;31(4):766-774.

39. De Nicolo A, Avataneo V, Rabbia F, et al. UHPLC-MS/MS method with sample dilution to test therapeutic adherence through quantification of ten antihypertensive drugs in urine samples. $J$ Pharm Biomed Anal. 2017;142:279-285.

40. Lawson AJ, Shipman KE, George S, Dasgupta I. A novel 'Dilute-and-Shoot' liquid chromatographytandem mass spectrometry method for the screening of antihypertensive drugs in urine. J Anal Toxicol. 2016;40(1):17-27. 
41. Patel P, Gupta PK, White CM, Stanley AG, Williams B, Tomaszewski M. Screening for nonadherence to antihypertensive treatment as a part of the diagnostic pathway to renal denervation. J Hum Hypertens. 2016;30(6):368-373.

42. Avataneo V, De Nicolo A, Rabbia F, et al. Therapeutic drug monitoring-guided definition of adherence profiles in resistant hypertension and identification of predictors of poor adherence. Br J Clin Pharmacol. 2018;84(11):2535-2543.

43. Stangier J, Schmid J, Turck D, et al. Absorption, metabolism, and excretion of intravenously and orally administered [14C]telmisartan in healthy volunteers. J Clin Pharmacol. 2000;40(12 Pt 1):1312-1322.

44. Kallner A. [Estimated GFR--value or illusion?]. Lakartidningen. 2009;106(1-2):40-43.

45. Assessment of kidney function. UpToDate; 2019. https://www.uptodate.com/contents/assessment-of-kidneyfunction?search=renal\%20clearanc\&source=search result\&selectedTitle=1 150\&usage type=de fault\&display rank=1\#H3. Accessed Mai 04, 2020.

46. Wong GW, Boyda HN, Wright JM. Blood pressure lowering efficacy of beta-1 selective beta blockers for primary hypertension. Cochrane Database Syst Rev. 2016;3:Cd007451.

47. Drug information. UpToDate 2019. https://www.uptodate.com. Accessed August 8, 2019.

48. Horikiri Y, Suzuki T, Mizobe M. Pharmacokinetics and metabolism of bisoprolol enantiomers in humans. J Pharm Sci. 1998;87(3):289-294.

49. The Norwegian Medicnes Manual for Health Personnel (Norsk legemiddelhåndbok). https://www.legemiddelhandboka.no. Accessed August 8, 2019.

50. Whirl-Carrillo M, McDonagh EM, Hebert JM, et al. Pharmacogenomics knowledge for personalized medicine. Clin Pharmacol Ther. 2012;92(4):414-417.

51. Molden E, Johansen PW, Boe GH, et al. Pharmacokinetics of diltiazem and its metabolites in relation to CYP2D6 genotype. Clin Pharmacol Ther. 2002;72(3):333-342.

52. Yamamoto T, Kubota T, Ozeki T, et al. Effects of the CYP3A5 genetic polymorphism on the pharmacokinetics of diltiazem. Clin Chim Acta. 2005;362(1-2):147-154.

53. Nakashima A, Kawashita $\mathrm{H}$, Masuda $\mathrm{N}$, et al. Identification of cytochrome $\mathrm{P} 450$ forms involved in the 4-hydroxylation of valsartan, a potent and specific angiotensin II receptor antagonist, in human liver microsomes. Xenobiotica. 2005;35(6):589-602.

54. Beermann B, Groschinsky-Grind M, Lindstrom B. Pharmacokinetics of bendroflumethiazide. Clin Pharmacol Ther. 1977;22(4):385-388.

55. Barchielli M, Dolfini E, Farina $\mathrm{P}$, et al. Clinical pharmacokinetics of lercanidipine. Cardiovasc Pharmacol. 1997;29(S1-S15). 
56. Ulm EH, Hichens M, Gomez HJ, et al. Enalapril maleate and a lysine analogue (MK-521): disposition in man. Br J Clin Pharmacol. 1982;14(3):357-362.

57. van Griensven JM, Schoemaker RC, Cohen AF, Luus HG, Seibert-Grafe M, Rothig HJ.

Pharmacokinetics, pharmacodynamics and bioavailability of the ACE inhibitor ramipril. Eur J Clin Pharmacol. 1995;47(6):513-518.

58. van Lier JJ, van Heiningen PN, Sunzel M. Absorption, metabolism and excretion of 14Ccandesartan and 14C-candesartan cilexetil in healthy volunteers. J Hum Hypertens. 1997;11 Suppl 2:S27-28.

59. Lo MW, Goldberg MR, McCrea JB, Lu H, Furtek Cl, Bjornsson TD. Pharmacokinetics of losartan, an angiotensin II receptor antagonist, and its active metabolite EXP3174 in humans. Clin Pharmacol Ther. 1995;58(6):641-649.

60. Oberbauer R, Krivanek $P$, Turnheim K. Pharmacokinetics and pharmacodynamics of the diuretic bumetanide in the elderly. Clin Pharmacol Ther. 1995;57(1):42-51.

61. Krause W, Karras J, Seifert W. Pharmacokinetics of canrenone after oral administration of spironolactone and intravenous injection of canrenoate-K in healthy man. Eur J Clin Pharmacol. 1983;25(4):449-453.

62. Chen J, Jiang B, Lou H, Xu Y, Shao R, Ruan Z. Dose proportionality and pharmacokinetics of eplerenone in healthy Chinese subjects. Drug Res (Stuttg). 2016;66(3):154-159. 
Figure Legends:

Figure 1. Factors influencing serum drug concentrations, constituting possible indications for TDM use.

Figure 2. Prescriptions from outside hospitals of cardiovascular drugs in DDD/1000 inhabitants/year during 2014-2018 in Norway. Data from the Norwegian Prescription Database.

CCBs: calcium channel blockers, ACEls: angiotensin-converting enzyme inhibitors, ARBs: angiotensin II receptor blockers, others: mainly alpha-blockers and centrally acting agents; DDD: daily defined doses.

Supplemental Digital Content:

Supplemental Digital Content 1. Xls 
Figure 1.

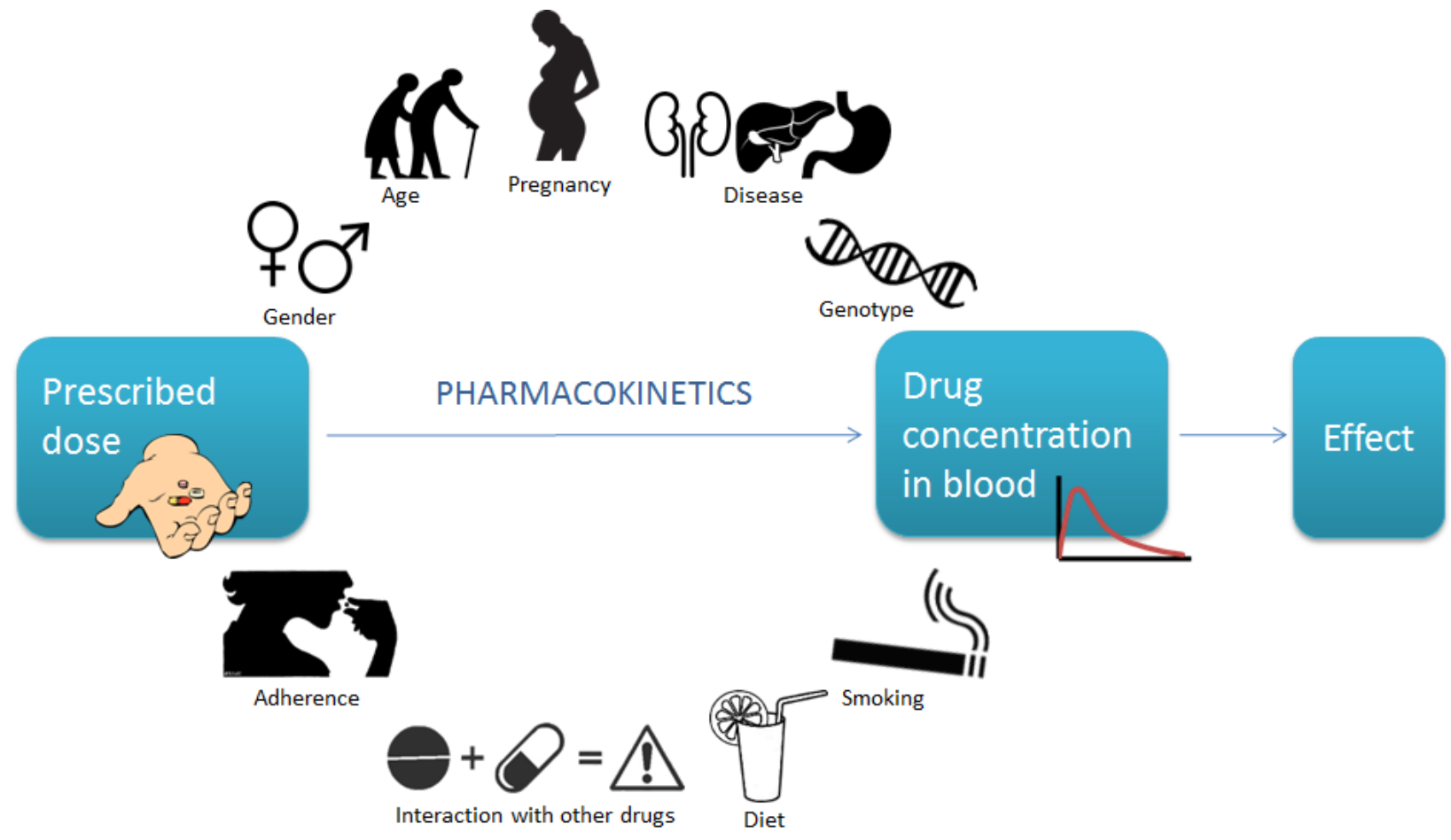

Figure 2.

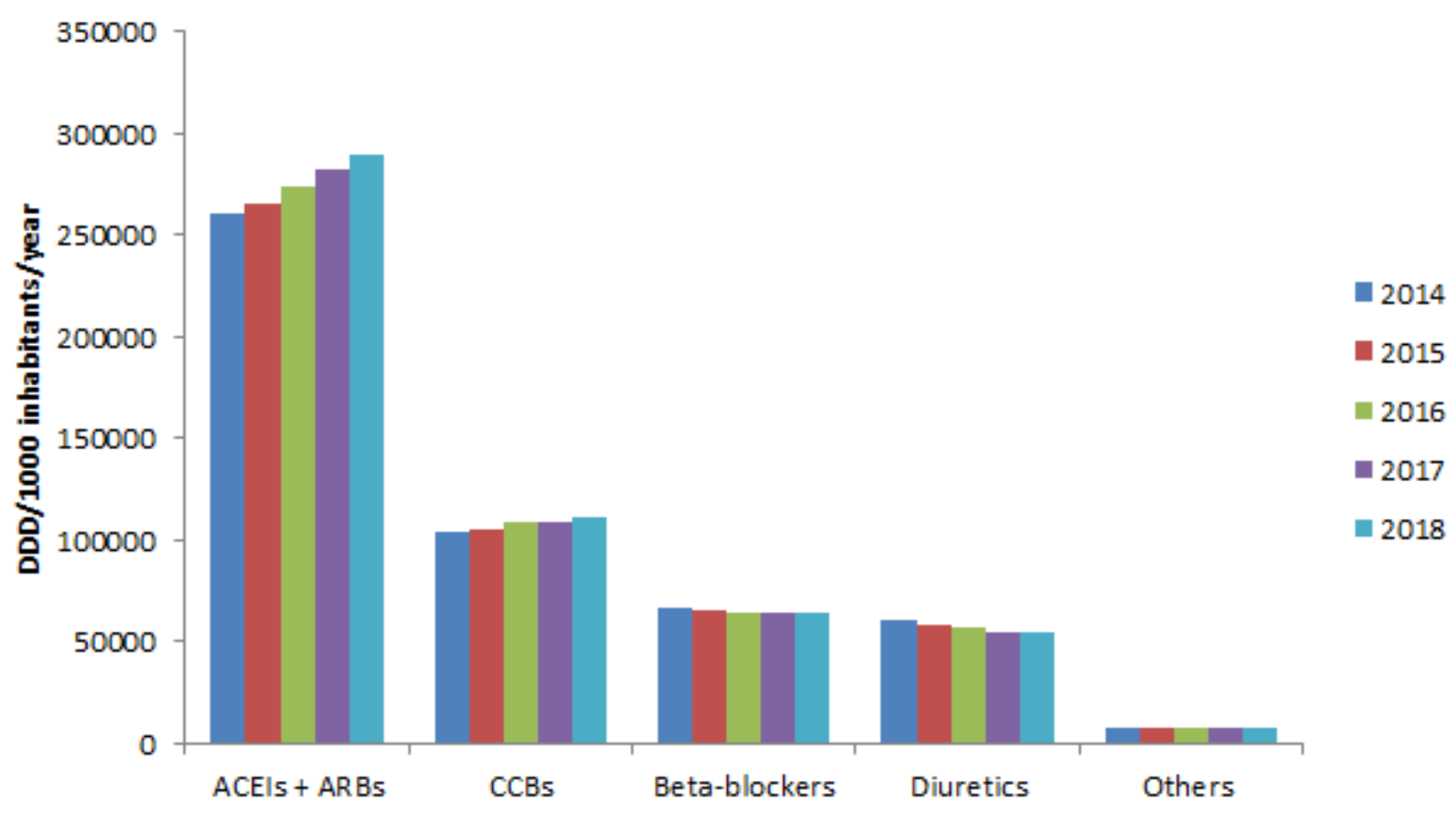

